D) Check for updates

Cite this: Polym. Chem., 2020, 11 6701

Received 29th July 2020,

Accepted 28th September 2020

DOI: $10.1039 / \mathrm{d} 0$ py01084g

rsc.li/polymers

\section{Functional polyimides based on diamine containing diarylethylene moieties and their photochromic mechanism studies $\uparrow$}

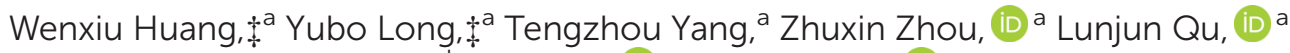 \\ Minming Wu, ${ }^{* a}$ Xiaolong Qi, ${ }^{b}$ Siwei Liu, (D) a Zhenguo Chi, (D) a Jiarui Xu ${ }^{a}$ and \\ Yi Zhang (iD *a
}

To expand the existing application conditions of photochromic polymers and enhance the tolerance of photochromic polymer electronic devices in extreme environments, a diamine monomer DTEDA bearing the diarylethylene (DTE) moiety was synthesized and polymerized with commercially available dihydrides to afford three polyimides (PIs, named DTEODPI, DTE6FPI and DTEHPMPI) through chemical imidization. These PIs realized reversible photo-triggered isomerization both in solution and in film state, with solution photoluminescence "on/off" effects. Semi-aromatic DTEHPMPI showed the largest contrast of color and fastest light response due to its local excited (LE) state. This research provides a simple method to prepare photochromic polymer materials with excellent comprehensive properties.

\section{Introduction}

Photochromic materials, which can be reversibly transformed into two isomers upon irradiation, might show significant differences in their physical and chemical properties, such as refractive index, absorbance, fluorescence intensity and dielectric constant under illumination. ${ }^{1}$ Therefore, they have great potential in various practical applications such as data storage, optoelectronic devices, sensing, tunable self-assembly morphology, super-resolution microscopy, anti-counterfeiting materials and other fields. ${ }^{2-6}$ Among the family of photochromes, including spiropyran, ${ }^{7}$ azobenzene, ${ }^{8}$ Schiff-base, ${ }^{9}$ triarylethylene ${ }^{10-12}$ and dithienylethene (DTE), ${ }^{13,14}$ DTE is regarded as the shining star due to its inherent bistable characteristics and excellent recyclability. Although in-depth research has been conducted on small molecule DTE materials, ${ }^{15}$ their poor thermal stability, inferior film-forming property and easy oxidation nature are still the key constraints;

\footnotetext{
${ }^{a}$ PCFM Lab, GD HPPC Lab, Guangdong Engineering Technology Research Centre for High-performance Organic and Polymer Photoelectric Functional Films, State Key Laboratory of Optoelectronic Materials and Technologies, School of Chemistry, Sun Yat-sen University, Guangzhou 510275, China. E-mail: wumm8@mail.sysu.edu.cn, ceszy@mail.sysu.edu.cn; Fax: +8620 84112222; Tel: +86 2084112222

${ }^{b}$ Guangdong Hinno-Tech Co., Ltd, Jiangmen 529000, China

$\dagger$ Electronic supplementary information (ESI) available: Materials and instrument information, ${ }^{1} \mathrm{H}$ NMR, ${ }^{13} \mathrm{C}$ NMR and IR spectra, DSC curves, and the solubility of the polyimides. See DOI: 10.1039/d0py01084g

$\$$ These authors contributed equally in this paper.
}

however, by introducing DTE moieties into polymers, all issues can be resolved. ${ }^{16}$

Generally, there are two strategies for introducing DTE moieties into polymers: (1) doping DTE derivatives into polymers, ${ }^{17}$ and (2) covalently incorporating DTE chromophores into the main or side chains of polymers. ${ }^{18}$ The former method has obvious drawbacks, with low concentration doping influencing the photochromic properties while high concentration doping readily causes aggregation and phase separation due to low compatibility between DTE small molecules and polymer macromolecules. ${ }^{19}$ The poor heat resistance of small molecule DTE dopants limits its application in the more demanding fields. Up to now, several kinds of DTE bonded functional polymer materials such as polycarbonate, ${ }^{20}$ polysiloxane, $^{21}$ polyurethane $e^{22,23}$ and other conjugated polymers $^{24,25}$ have been synthesized and investigated. Much progress in photochromic polymer materials has been made in terms of color changing speed and fatigue resistance, ${ }^{26}$ while other properties, such as high and low temperature resistance and extreme environmental resistance, have been neglected, and they are of great importance when put to practical use. To overcome the problems mentioned above, we considered combining DTE moieties with polymer materials possessing excellent properties. Compared with the polymers mentioned above, polyimides (PIs), as a family of functional polymer materials showing excellent intrinsic comprehensive performance, surpass other photochromic polymer materials in high glass transition temperature and high decomposition temperature, with superior film-forming properties, simple 
synthesis and easy mass production..$^{27-30}$ More importantly, PI could maintain its good performance even under extreme conditions. In addition, introducing DTE moieties into the polymer backbone would improve its quantum yield, which would help in improving its photochromic properties. ${ }^{20,31}$

Herein, three PIs (named DTE6FPI, DTEHPMPI, and DTEODPI) were prepared via chemical imidization, with a DTE containing diamine monomer DTEDA and three commercially available dianhydrides (6FDA, ODPA, and HPMDA). All three PIs are photochromic both in solution and in film state, with the colorless open-ring form turning into a red closed-ring form under ultraviolet (UV) light. The process is reversible when the red closed-ring form is irradiated with visible light and it turns to a colorless open-ring form. This is the first report on photochromic polyimides containing DTE moieties. The photochromic mechanism is speculated through theoretical calculations, and DTEHPMPI with a semi-aromatic structure had the fastest UV response and highest contrast color. The reversible photochromic property makes PIs advantageously applicable as UV sensors, anti-fake materials, smart windows, optoelectronic devices and many other fields.

\section{Results and discussion}

\section{Synthesis and characterization of monomers}

The diamine monomer DTEDA was obtained via a three-step synthesis route (Scheme 1) according to an earlier report. ${ }^{32}$ The Friedel-Crafts acylation of 1 with glutaryl dichloride was performed in anhydrous $\mathrm{CH}_{2} \mathrm{Cl}_{2}$ to obtain the colorless Dione. Afterwards the McMurry reaction was carried out to generate DTE2Cl, which can be functionalized using $n$-BuLi and tributyl borate in anhydrous THF, and the chlorine of DTE2Cl was sub-
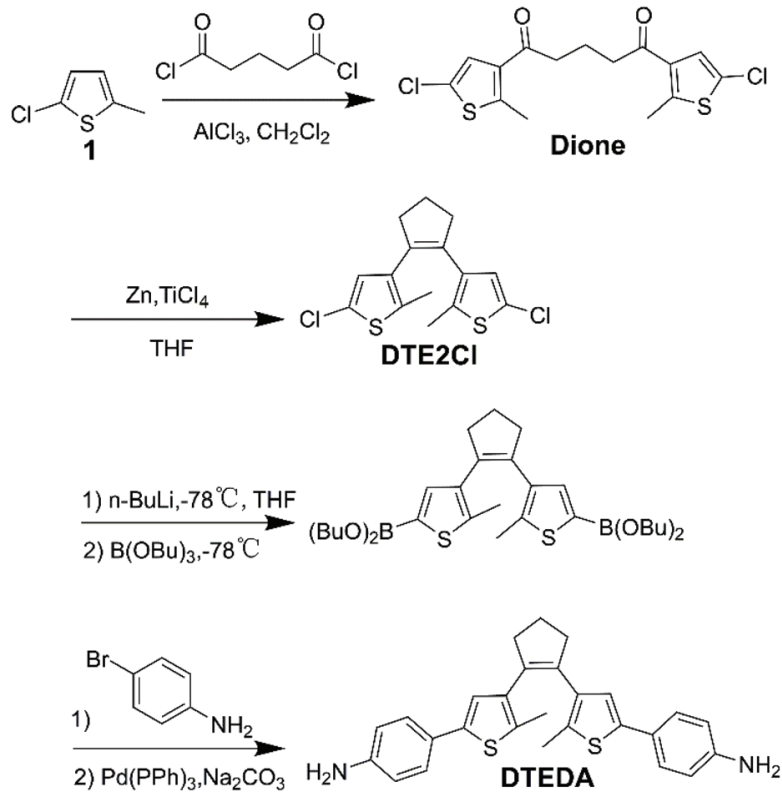

Scheme 1 Synthesis routes of diamine monomers DTEDA. stituted by $-\mathrm{B}(\mathrm{OBu})_{2}$ to form an intermediate, which could react with 4-bromoaniline by Suzuki cross-coupling reaction to afford the desired diamine monomer DTEDA. The intermediates and product DTEDA were confirmed by ${ }^{1} \mathrm{H}$ NMR, ${ }^{13} \mathrm{C}$ NMR, IR and mass spectra, which are shown in the ESI. $\dagger$

\section{Synthesis and characterization of polyimides}

DTEDA was polymerized with three commercial dianhydride monomers 1,2,4,5-cyclohexanetetracarboxylic dianhydride (HPMDA), 4,4'-(hexafluoroisopropylidene)diphthalic anhydride (6FDA) and 4,4-oxydiphthalic anhydride (ODPA) to prepare three PIs (DTE6FPI, DTEHPMPI, and DTEODPI). The preparation process of PIs is illustrated as follows. Equal molar amounts of DTEDA and dianhydride were mixed together in anhydrous dimethylformamide (DMF) and stirred at zero temperature to form viscous poly(amic acid) (PAA) solution, with solid contents of $15 \%-30 \%$. Pyridine and acetic anhydride were added at room temperature to chemically convert PAAs into PIs. The solutions of PIs were subsequently poured into methanol to yield three novel PIs bearing DTE moieties (Scheme 2). As a result of complete imidization, the infrared absorption bands at $3500 \mathrm{~cm}^{-1}-3300 \mathrm{~cm}^{-1}$ belong to the $\mathrm{N}-\mathrm{H}$ group of PAAs that disappeared, while the characteristic absorption peaks of the PI imide groups at about $1784 \mathrm{~cm}^{-1}$ $1712 \mathrm{~cm}^{-1}(\mathrm{C}=\mathrm{O}$ asymmetrical and symmetrical stretching $)$ and $1353 \mathrm{~cm}^{-1}(\mathrm{C}-\mathrm{N}-\mathrm{C}$ stretching) arose. In addition, the stretching vibrations of the $-\mathrm{CH}_{2}$ and $-\mathrm{CH}_{3}$ groups assigned to the central cycloalkene ring clearly appeared at $2960 \mathrm{~cm}^{-1}$ $2840 \mathrm{~cm}^{-1}$, which proved the successful introduction of the DTE group to the PIs. The intrinsic viscosities of DTE6FPI, DTEHPMPI and DTEODPI in NMP were $0.25 \mathrm{dL} \mathrm{g}^{-1}, 0.18 \mathrm{dL}$ $\mathrm{g}^{-1}$, and $0.73 \mathrm{dL} \mathrm{g}^{-1}$, respectively.

\section{Thermal properties}

Thermal properties of PIs were investigated by thermogravimetric analyses (TGA) and differential scanning calorimetry (DSC), as shown in Table 1. These three PIs showed excellent thermal stability, with $5 \%$ weight loss temperatures $\left(T_{\mathrm{d} 5 \%}\right)$ of $441{ }^{\circ} \mathrm{C}$ (DTEHPMPI), $492{ }^{\circ} \mathrm{C}$ (DTE6FPI) and $490{ }^{\circ} \mathrm{C}$ (DTEODPI) under $\mathrm{N}_{2}$, respectively. The aromatic imide structures made the $T_{\mathrm{d} 5 \%}$ of DTE6FPI and DTEODPI higher than that of DTEHPMPI. Based on the DSC curves, we found that all the PIs had a high glass temperature $\left(T_{\mathrm{g}}\right)$, within the range of

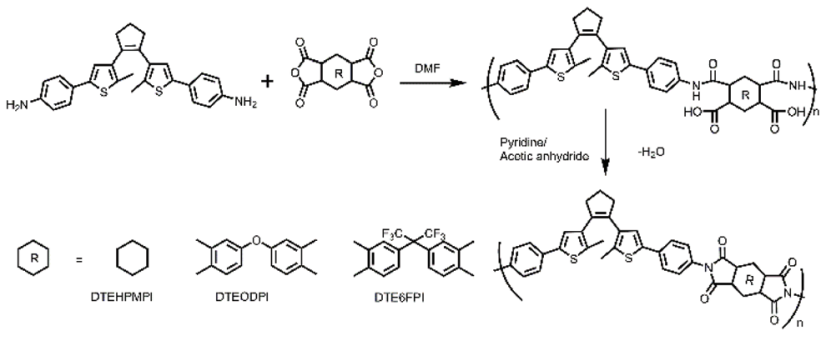

Scheme 2 Synthesis routes of polyimides DTEHPMPI, DTEODPI and DTE6FPI. 
Table 1 Thermal properties of polyimide films

\begin{tabular}{llll}
\hline Polyimide & $T_{\mathrm{g}}{ }^{a}$ & $T_{\mathrm{d}}{ }^{b}$ & Char yield $^{c}(\mathrm{wt} \%)$ \\
\hline DTE6FPI & 306 & 492 & 44 \\
DTEHPMPI & 278 & 441 & 9 \\
DTEODPI & 295 & 490 & 35
\end{tabular}

${ }^{a}$ Measured by DSC at a heating rate of $10{ }^{\circ} \mathrm{C} \min ^{-1} \cdot{ }^{b}$ Measured by TGA at a heating rate of $20^{\circ} \mathrm{C} \mathrm{min}{ }^{-1}$ in nitrogen. ${ }^{c}$ Residual weight percentage at $850{ }^{\circ} \mathrm{C}$ under $\mathrm{N}_{2}$.
250-280 ${ }^{\circ} \mathrm{C}$ (Fig. S3 in ESI $\dagger$ ). Besides, good solubility in common solvents made them suitable for efficient and simple spin-coating, printing or roll-to-roll processing (Table $\mathrm{S} 1$ in the ESI†).

Photochromic properties of polyimides

To assess the photochromic properties of PIs, UV-Vis experiments were conducted in NMP solution (Fig. 1) and in film state (Fig. 2) at room temperature. The absorption peaks in solution mainly appeared at $300 \mathrm{~nm}$ and $318 \mathrm{~nm}$ before
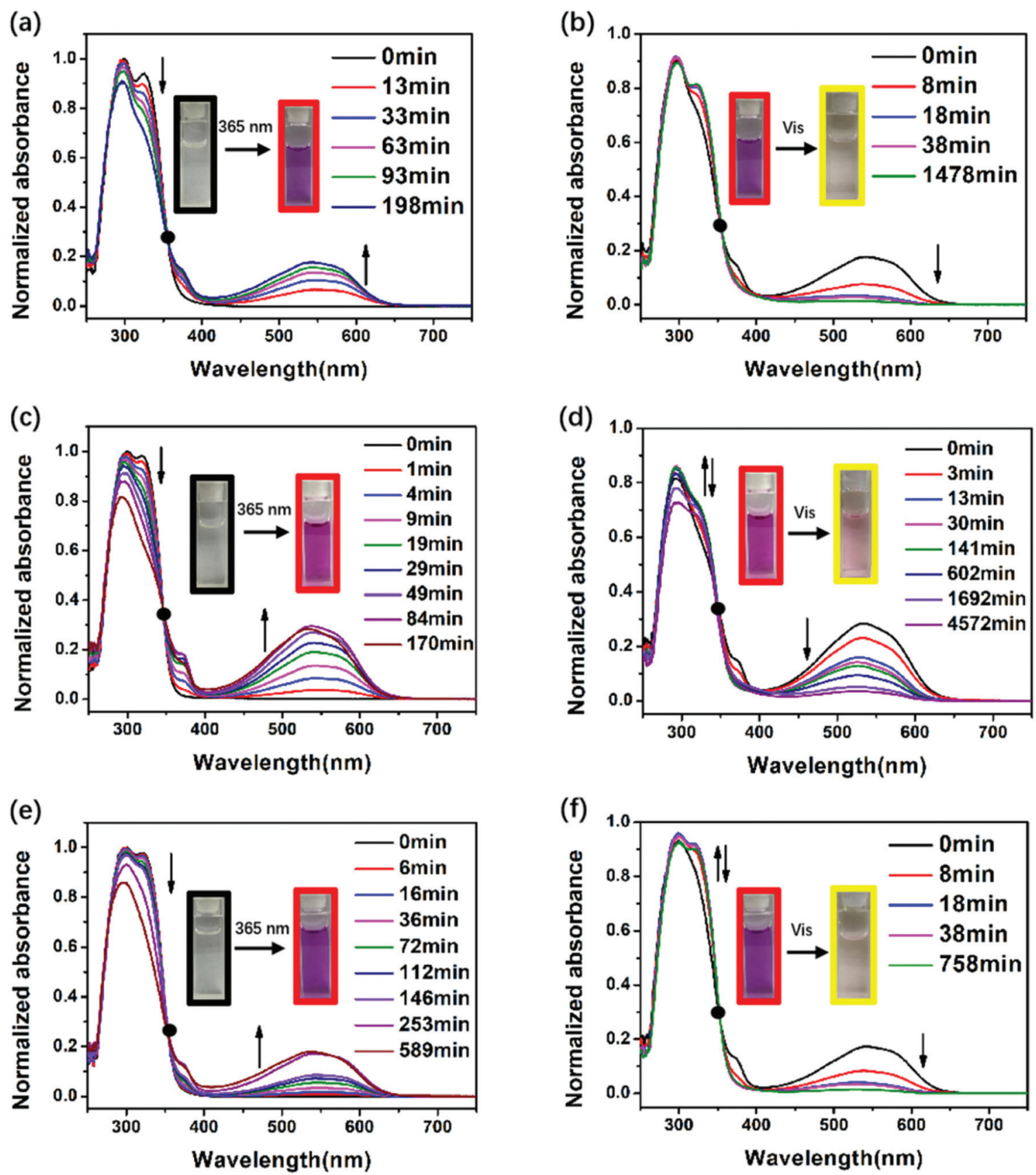

Fig. 1 UV-Vis spectra of DTE6FPI ( $a$ and b), DTEHPMPI (c and d), and DTEODPI (e and f) in NMP solution (0.05 mmol $\mathrm{L}^{-1}$ ) during illumination with $365 \mathrm{~nm}$ UV light ( $a, c$ and e) or visible light ( $b, d$ and $f$ ). 
(a)

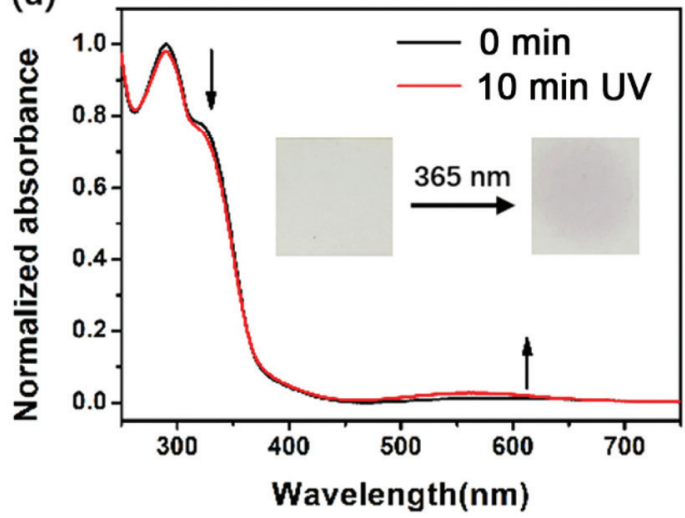

(c)

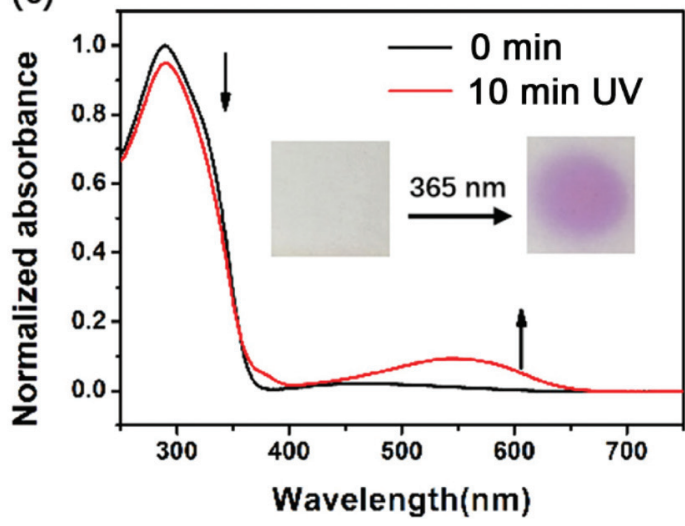

(e)

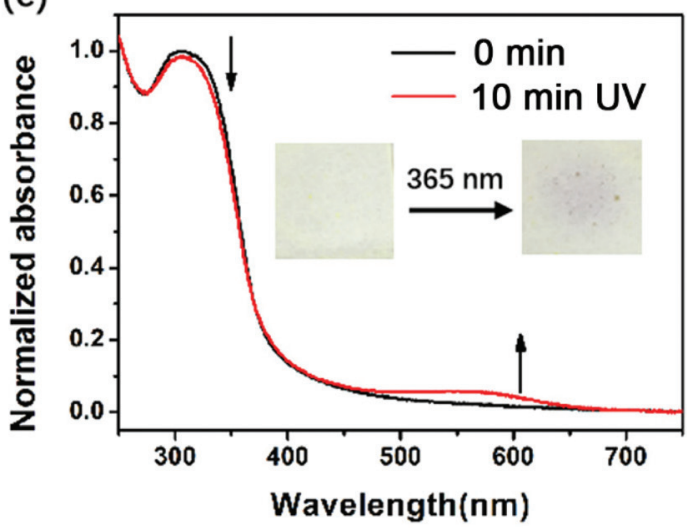

(b)

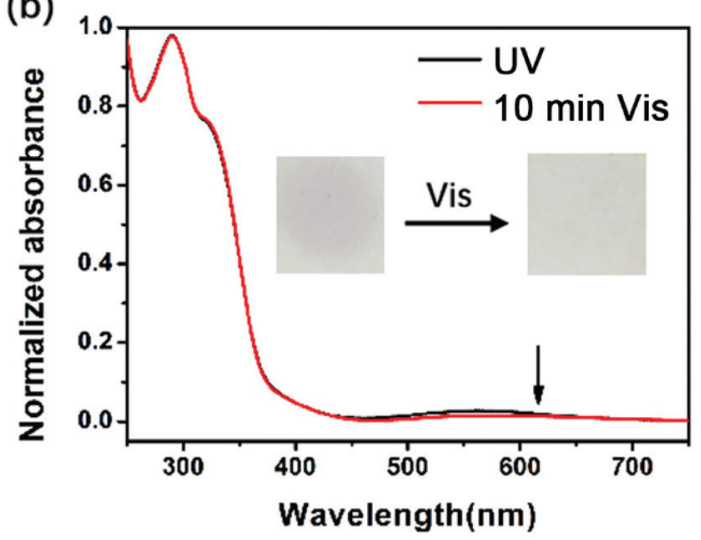

(d)

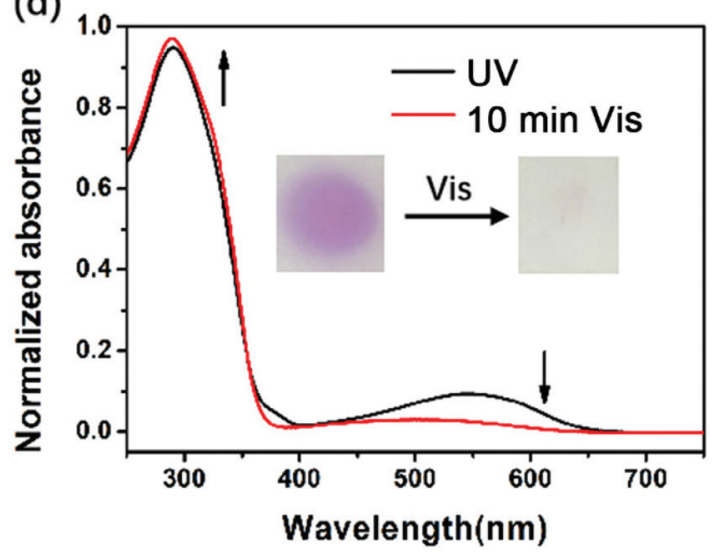

(f)

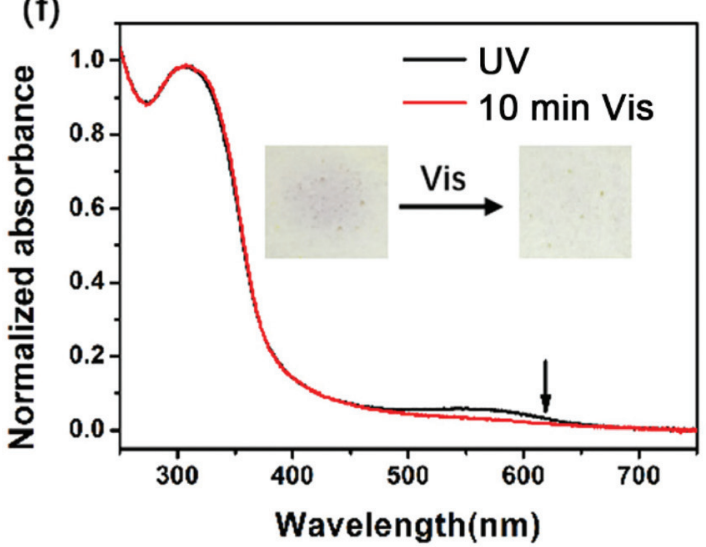

Fig. 2 UV-Vis spectra of DTE6FPI ( $a$ and b), DTEHPMPI (c and d), and DTEODPI (e and f) films during illumination with $365 \mathrm{~nm}$ UV light (a, c and e) or visible light (b, $d$ and $f$ ).

irradiation. When exposed to $365 \mathrm{~nm}$ UV light, a new absorption peak in the visible region $(540 \mathrm{~nm})$ appeared and its intensity increased with time, accompanied by the decrease of the absorption peak in the short wavelength region $(300 \mathrm{~nm}$ and $318 \mathrm{~nm}$ ), changing the color from colorless to red. This can be attributed to the photoisomerization of DTE, which changed from an open-ring form to a closed-ring form under UV illumination, leading to larger conjugation and long wavelength light absorption. After irradiation for a period of time, the $540 \mathrm{~nm}$ peak no longer increases, indicating that the photostationary state (PSS) is reached where two forms coexisted simultaneously in solution. Along with the UV-vis spectrum which showed an opposite change to the above results, the red solutions of the three PIs could be decolorized under visible light $(>450 \mathrm{~nm})$. The decolorization process proved that the closed-ring form could return to the initial open-ring form. It is noteworthy that a decrease in the short wavelength region (300 $\mathrm{nm}$ and $318 \mathrm{~nm}$ ) was observed when they were exposed to visible light for longer than $38 \mathrm{~min}$ (DTE6FPI), $141 \mathrm{~min}$ (DTEHPMPI) and $38 \mathrm{~min}$ (DTEODPI). This phenomenon 
might be due to the fact that partial ring-opened isomers absorbed a small amount of UV light that leaked from the filter and the ring-closing reaction occurred again. Nearly uniform absorption wavelengths of the open- and closed-ring forms were monitored for these PIs, demonstrating the negligible influence of the dihydrides on them. Fig. 2 shows the film state UV-Vis spectra, which clearly indicate that reversible photo-isomerization existed in film state as well, with similar spectra to their solution state spectra. The three DTE containing PI films exhibited the same behavior under $365 \mathrm{~nm}$ UV irradiation or visible light illumination as their solutions. As is shown in Fig. 2, DTEHPMPI had the largest contrast of color and fastest light response over DTE6FPI and DTEODPI.

\section{Photofluorescence switching behaviors of the polyimides}

Fig. 3 exhibits the fluorescence spectra "on/off" switch of these three PIs in NMP, with intense emission peaks observed at $469 \mathrm{~nm}$ (DTE6FPI), $456 \mathrm{~nm}$ (DTEHPMPI), and $465 \mathrm{~nm}$ (DTEODPI), respectively. The fluorescence spectra were quenched upon irradiation with $365 \mathrm{~nm}$ UV light and almost returned to their initial intensity with visible light illumination $(>450 \mathrm{~nm})$. It is worth noting that there were significant spectral overlaps between the absorptions of closed-ring forms and emission of open-ring forms (Fig. 4). We assumed that the efficient energy transfer between the two isomers was responsible for this phenomenon. Due to the low detection limit of fluorescence intensity, we may use them as ultraviolet light sensors.
Table 2 Theoretical analysis for model compounds

\begin{tabular}{llll}
\hline Compound & $\mathrm{S} 1$ & Energy $(\mathrm{nm} / \mathrm{eV})$ & $f$ \\
\hline MO-DTE6F-O & $\mathrm{H} \rightarrow \mathrm{L}$ & $520 / 2.39$ & 0.0008 \\
MO-DTE6F-C & $\mathrm{H} \rightarrow \mathrm{L}$ & $803 / 1.54$ & 0.0003 \\
MO-DTEHPM-O & $\mathrm{H} \rightarrow \mathrm{L}$ & $338 / 3.67$ & 0.31 \\
MO-DTEHPM-C & $\mathrm{H} \rightarrow \mathrm{L}$ & $597 / 2.08$ & 0.72 \\
MO-DTEOD-O & $\mathrm{H} \rightarrow \mathrm{L}$ & $500 / 2.48$ & 0.0005 \\
MO-DTEOD-C & $\mathrm{H} \rightarrow \mathrm{L}$ & $754 / 1.64$ & 0.0013 \\
\hline
\end{tabular}
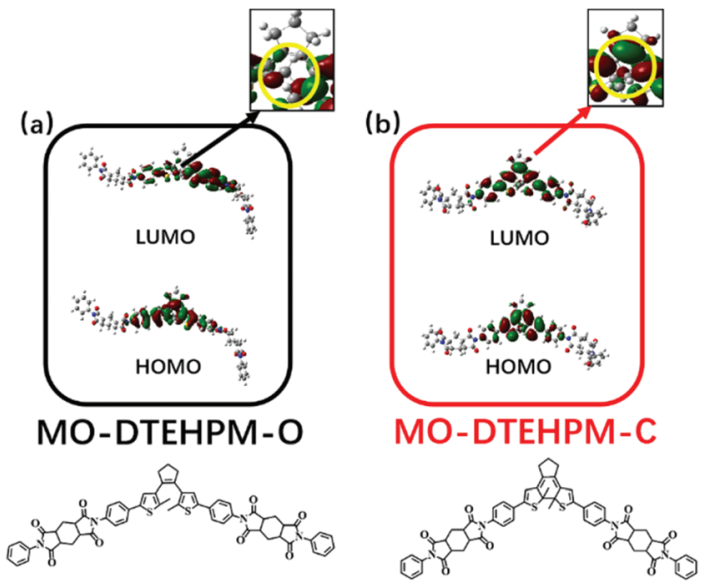

Fig. 5 The frontier molecular orbitals of MO-DTEHPM-O (a), and MO-DTEHPM-C (b).
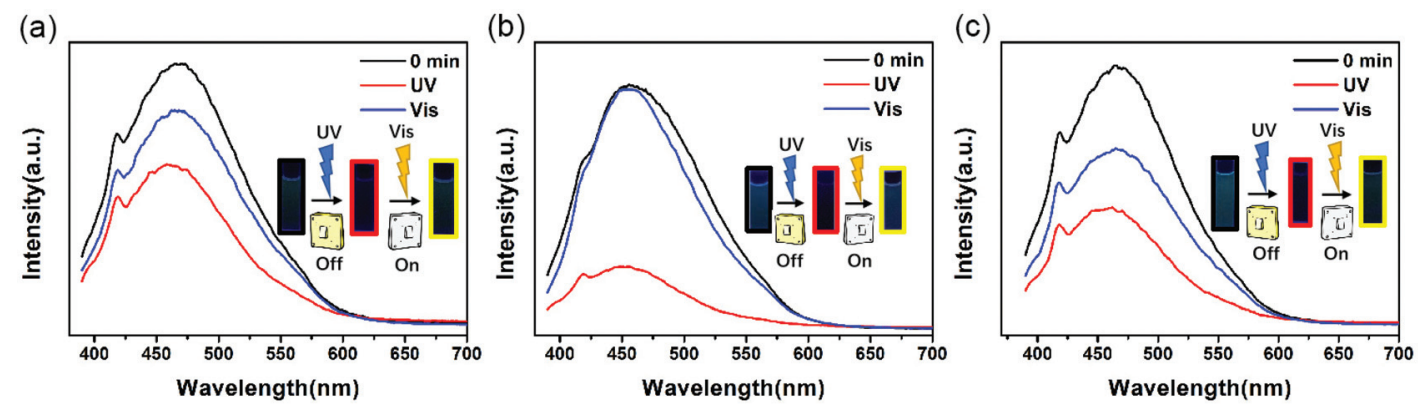

Fig. 3 Change of emission spectra of DTE6FPI (a), DTEHPMPI (b), and DTEODPI (c) before irradiation (black line), after $365 \mathrm{~nm}$ irradiation (red line) and under visible light (blue line).
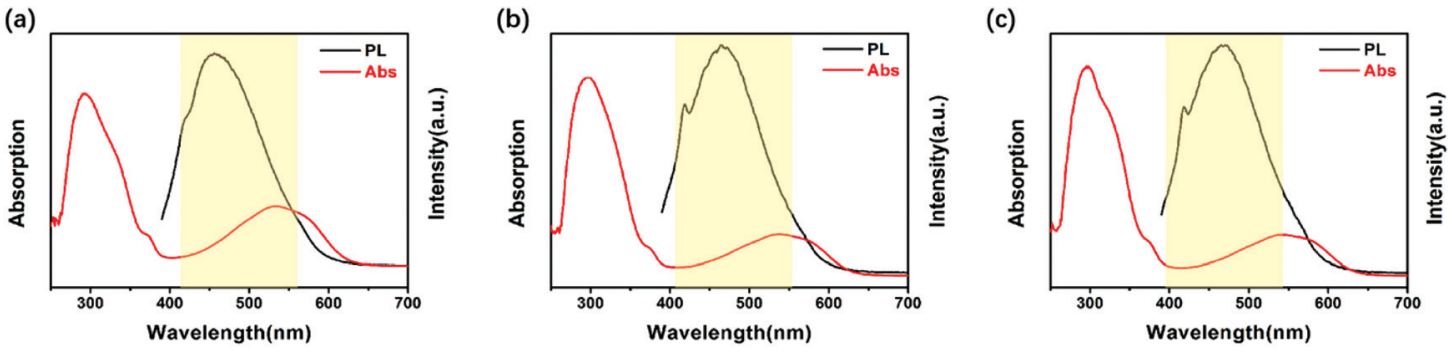

Fig. 4 UV-Vis spectra of closed ring forms (red line) and emission spectra of open ring forms (black line) of DTE6FPI (a), DTEHPMPI (b), and DTEODP (c). 

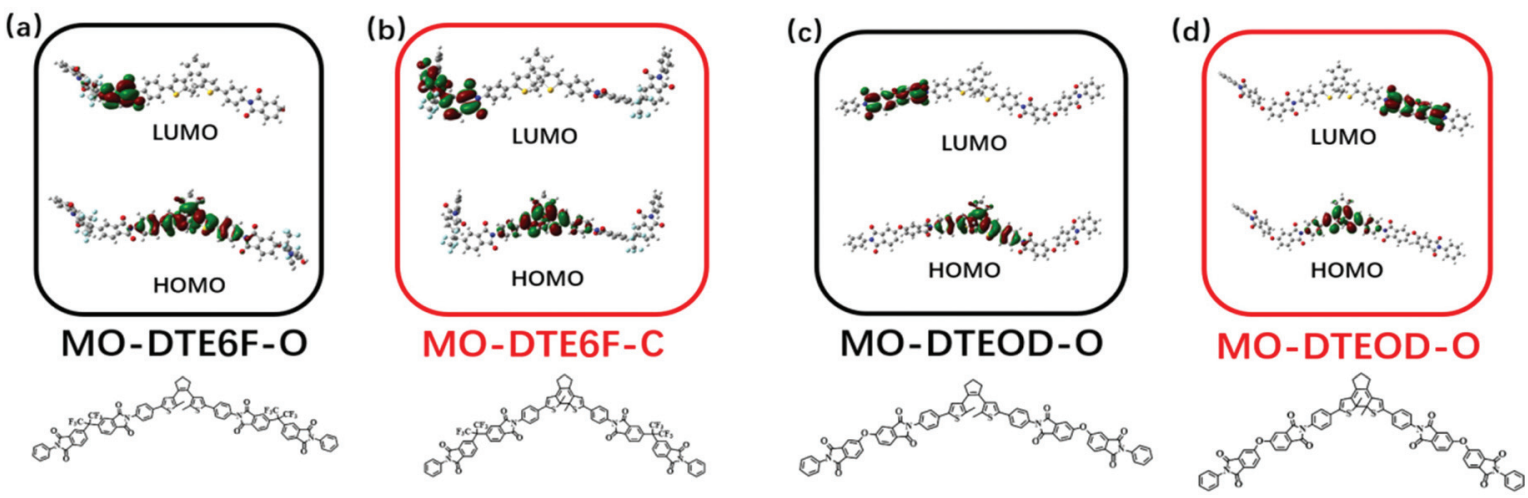

Fig. 6 The frontier molecular orbitals of MO-DTE6F-O (a), MO-DTE6F-C (b), MO-DTEOD-O (c), and MO-DTEOD-C (d).

Theoretical analysis of the photochromic mechanism

To investigate the photochromic mechanism, we designed three model compounds (MO-DTEHPM, MO-DTE6F, and MO-DTEOD) according to the polymer repeating unit (Table 2). Their openring $(\mathrm{O})$ and closed-ring $(\mathrm{C})$ forms were optimized and calculated using time-dependent density functional theory (TD-DFT) for the frontier molecular orbitals with the Gaussian 09 program package. As we can see from Fig. 5, the highest occupied molecular orbital (HOMO) and lowest unoccupied molecular orbital (LUMO) of MO-DTEHPM-O were mainly concentrated around the DTE moiety and two benzene rings connected to thiophene. The first excited state (S1) is the transition from the HOMO to LUMO. The overlap of electron clouds between the two orbitals is large, and the oscillator strength $(f)$ is 0.31 , which is a typical feature of the locally excited (LE) state and is beneficial for electron transition. The wave functions of activated carbon atoms on the LUMO are in the same phase (shown in red in Fig. 5a), indicating a tendency of forming a bonding orbital. Furthermore, the energy for the first excitation $(338 \mathrm{~nm})$ matched well with the experimental result $(365 \mathrm{~nm})$. So, we can deduce that MO-DTEHPM-O could absorb a $365 \mathrm{~nm}$ photon and transform into MO-DTEHPM-C. Similarly, the S1 of MO-DTEHPM-C presents an LE state (Fig. 5b). The activated carbon atoms in the HOMO show a bonding property while the LUMO is antibonding. It can be inferred that the electrons are excited from the HOMO to LUMO, and then MO-DTEHPM-O is formed. The photoisomerization of the aromatic structure (MO-DTE6F and MO-DTEOD) is shown in Fig. 6. The HOMO-LUMO separations showed that S1 is an intramolecular charge-transfer (CT) transition with small oscillator strength (0.0008 of MO-DTE6F-O, 0.0003 of MO-DTE6F-C, 0.0005 of MO-DTEOD-O, and 0.0013 of MO-DTEOD-C). The above results indicate that the semi-aromatic structure is more beneficial for energy absorption and the occurrence of photoisomerization.

\section{Conclusions}

In this article, we reported the synthesis of a symmetrical diamine DTEDA containing DTE via a three-step procedure and polymerization with three commercial dianhydrides to afford three PIs (DTEODPI, DTE6FPI, and DTEHPMPI). All three PIs realized reversible photo-triggered isomerization both in solution and in film state, with photoluminescence "on/off" effects in solution. Among them, the semi-aromatic DTEHPMPI polymer had the largest contrast of color and fastest light response due to its LE state electron distribution over the DTE fragment. The research provides a simple method to prepare photochromic polymer materials with excellent comprehensive properties.

\section{Experimental}

Raw materials, synthesis route and instrumentation are presented in the ESI. $\dagger$

\section{Author contributions}

W. X. Huang, Y. B. Long, M. M. Wu and Y. Zhang conceived and designed the experiments. W. X. Huang, Y. B. Long, Z. X. Zhou, L. J. Qu, and X. L. Qi performed the experiments. All the authors were involved in the analyses and interpretation of data. W. X. Huang, Y. B. Long, and M. M. Wu wrote the manuscript with the help of Z. G. Chi, Y. Zhang, and J. R. Xu.

\section{Conflicts of interest}

There are no conflicts of interest to declare.

\section{Acknowledgements}

The financial support by the Science and Technology Project of Guangdong Province (No. 2015B090915003, 2019B040401002 and 2020B010182001), the National Natural Science Foundation of China (No. 51873239 and 51373204), the National 973 Program of China (No. 2014CB643605), and 
the Leading Scientific, Technical and Innovation Talents of Guangdong Special Support Program (No. 2016TX03C295) is gratefully acknowledged.

\section{References}

1 M. Irie, Chem. Rev., 2000, 100, 1685-1716.

2 H. Tian, Angew. Chem., Int. Ed., 2010, 49, 4710-4712.

3 B. Oruganti, P. P. Kalapos, V. Bhargav, G. London and B. Durbeej, J. Am. Chem. Soc., 2020, 142, 13941-13953.

4 N. Shao, J. Jin, H. Wang, J. Zheng, R. H. Yang, W. H. Chan and Z. Abliz, J. Am. Chem. Soc., 2010, 132, 725-736.

5 X. Y. Yao, T. Li, J. Wang, X. Ma and H. Tian, Adv. Opt. Mater., 2016, 4, 322-1349.

6 S. S. Wang, Y. Y. Zhou, L. L. Zhu, J. J. Zhang, Q. Zou, T. Zeng and W. B. Chen, Chem. Commun., 2017, 53, 95709573.

7 M. Suda, N. Takashina, S. Namuangruk, N. Kungwan, H. Sakurai and H. M. Yamamoto, Adv. Mater., 2017, 29, 1606833.

8 M. M. Lerch, M. J. Hansen, W. A. Velema, W. Szymanski and B. L. Feringa, Nat. Commun., 2016, 7, 12504.

9 E. Hadjoudis and I. M. Mavridis, Chem. Soc. Rev., 2004, 33, 579-588.

10 T. Yu, D. P. Ou, L. Y. Wang, S. Z. Zheng, Z. Y. Yang, Y. Zhang, Z. G. Chi, S. W. Liu, J. R. Xu and M. P. Aldred, Mater. Chem. Front., 2017, 1, 1900-1904.

11 T. Yu, Z. Y. Yang, T. G. Luan, Z. Mao, Y. Zhang, S. W. Liu, J. R. Xu, Z. G. Chi and M. R. Bryce, Chem. Sci., 2016, 7, 5302-5306.

12 L. Y. Wang, T. Yu, Z. L. Xie, X. J. Chen, Z. Yang, Y. Zhang, M. P. Aldred and Z. G. Chi, J. Mater. Chem. C, 2018, 6, 8832-8838.

13 A. Peters and N. R. Branda, Adv. Mater. Opt. Electron., 2000, 10, 245-249.

14 Z. W. Zhang, J. J. Zhang, B. Wu, X. Li, Y. Chen, J. H. Huang, L. L. Zhu and H. Tian, Adv. Opt. Mater., 2018, 6, 1700847.

15 M. Herder, B. M. Schmidt, L. Grubert, M. Pätzel, J. Schwarz and S. Hecht, J. Am. Chem. Soc., 2015, 137, 2738-2747.
16 R. Singh, H. Y. Wu, A. K. Dwivedi, A. Singh, C. M. Lin, P. Raghunath, M. C. Lin, T. K. Wu, K. H. Wei and H. C. Lin, J. Mater. Chem. C, 2017, 5, 9952-9962.

17 O. Nevskyi, D. Sysoiev, J. Dreier, S. C. Stein, A. Oppermann, F. Lemken, T. Janke, J. Enderlein, I. Testa, T. Huhn and D. Wöll, Small, 2018, 14, 1703333.

18 F. Stellacci, C. Bertarelli, F. Toscano, M. C. Gallazzi, G. Zotti and G. Zerbi, Adv. Mater., 1999, 11, 292-295.

19 J. Yang, Z. G. Chi, W. H. Zhu, B. Z. Tang and Z. Li, Sci. China: Chem., 2019, 62, 1090-1098.

20 H. Tian and H. Y. Tu, Adv. Mater., 2000, 12, 1597-1600.

21 J. Biteau, F. Chaput, K. Lahlil, J. P. Boilot, G. M. Tsivgoulis, J. M. Lehn, B. Darracq, C. Marois and Y. Lévy, Chem. Mater., 1998, 10, 1945-1950.

22 G. Pariani, R. Castagna, G. Dassa, S. Hermes, C. Vailati, A. Bianco and C. Bertarelli, J. Mater. Chem., 2011, 21, 13223-13231.

23 L. Oggioni, C. Toccafondi, G. Pariani, L. Colella, M. Canepa, C. Bertarelli and A. Bianco, Polymers, 2017, 9, 462.

24 J. X. Bu, K. Watanabe, H. Hayasaka and K. Akagi, Nat. Commun., 2014, 5, 3799.

25 K. Watanabe, H. Hayasaka, T. Miyashita, K. Ueda and K. Akagi, Adv. Funct. Mater., 2015, 25, 2794-2806.

26 G. Pariani, M. Quintavalla, L. Colella, L. Oggioni, R. Castagna, F. Ortica, C. Bertarelli and A. Bianco, J. Phys. Chem. C, 2017, 121, 23592-23598.

27 Y. W. Liu, Z. X. Zhou, L. J. Qu, B. Zou, Z. Q. Chen, Y. Zhang, S. W. Liu, Z. G. Chi, X. D. Chen and J. R. Xu, Mater. Chem. Front., 2017, 1, 326-337.

28 Z. X. Zhou, Y. Zhang, S. W. Liu, Z. G. Chi, X. D. Chen and J. R. Xu, J. Mater. Chem. C, 2016, 4, 10509-10517.

29 Z. X. Zhou, W. X. Huang, Y. B. Long, Y. Q. Chen, Q. X. Yu, Y. Zhang, S. W. Liu, Z. G. Chi, X. D. Chen and J. R. Xu, J. Mater. Chem. C, 2017, 5, 8545.

30 L. J. Qu, L. S. Tang, R. X. Bei, J. Zhao, Z. G. Chi, S. W. Liu, X. D. Chen, M. P. Aldred, Y. Zhang and J. R. Xu, ACS Appl. Mater. Interfaces, 2018, 10, 11430-11435.

31 F. Liu, S. Bi, X. Wang, X. Leng, M. Han, B. Xue, Q. Li, H. Zhou and Z. Li, Sci. China: Chem., 2019, 62, 739-745.

32 C. M. Yu, B. C. Hu, C. Liu and J. T. Li, J. Phys. Org. Chem., 2017, 30, e3584, DOI: 10.1002/poc.3584. 